\title{
A LINGUAGEM ESCRITA E O DESENVOLVIMENTO INTELECTUAL DA CRIANÇA EM IDADE ESCOLAR: REFLEXÕES À LUZ DA TEORIA HISTÓRICO CULTURAL
}

\author{
Fatima Souza Francioli ${ }^{1}$ \\ Dhttp://orcid.org/0000-0001-8373-7056 \\ João Júnior Bonfim Joia Pereira ${ }^{2}$ \\ (1) http://orcid.org/0000-0003-3290-2546
}

Resumo: Este artigo tem como objetivo analisar o desenvolvimento da linguagem escrita e o desenvolvimento intelectual da criança em idade escolar, com destaque para os estágios da pré-história da escrita descritos por Luria (2006). O estudo é de cunho bibliográfico e à luz dos fundamentos da teoria histórico-cultural, procura evidenciar que, no ambiente escolar, o trabalho do professor se apresenta como um diferencial para o desenvolvimento da linguagem escrita na criança, de forma intencional e objetiva, levando em conta o caminho já percorrido por ela. Como resultado, observa-se que quando a atividade está de acordo com o nível de desenvolvimento da criança, promoverá nela um nível mais elevado, o que propiciará a possibilidade de se apropriar de conhecimentos mais complexos. Em outras palavras, a aprendizagem promove 0 desenvolvimento psíquico da criança e este, por sua vez, possibilita novas aprendizagens.

Palavras-chave: Linguagem escrita. Estágios da pré-escrita. Desenvolvimento intelectual da criança.

1 Doutora em Educação Escolar pela UNESP. Professora do Programa de Pós-graduação PPIFOR e do Colegiado de Pedagogia. Área: práticas de ensino. Líder do grupo de pesquisa - GTPEC - Estudos das teorias e práticas pedagógicas na perspectiva crítica da educação escolar. E-mail: fas.francioli@hotmail.com

2 Mestre em Ensino: Formação Docente Interdiscplinar (PPIFOR) na Universidade Estadual do Paraná (UNESPAR) - Campus de Paranavaí. Professor Pedagogo da Rede Estadual do Paraná e professor dos anos iniciais do ensino fundamental do município de Alto Paraná-PR. E-mail: joaojoia25@gmail.com 


\section{THE WRITTEN LANGUAGE AND INTELECTUAL DEVELOPMENT OF SCHOOLCHILDREN: REFLECTING IN THE LIGHT OF THE HISTORICAL- CULTURAL THEORY}

Abstract: This article aims to analyze the development of schoolchildren's written language development and intellectual development, with emphasis on the stages of the early history of writing described by Luria (2006). This is a bibliographical study on the grounds of the historical-cultural theory, which seeks to highlight how the teacher's work in the school environment, intentionally and objectively represents a differential in the development of children's writing, taking into account their already reached milestones. As a result, it is possible to observe that when assigned activities are on a par with the child's development, it will increase its level, which opens the way to their assimilating more complex ideas. In other words, leaning can promote a child's psychic development, which by itself allows for the learning possibilities.

Keywords: Written language. Stages of prewriting. Children's intellectual development.

\section{EL LENGUAJE ESCRITO Y EL DESARROLLO INTELECTUAL DEL NIÑO EN EDAD ESCOLAR: REFLEXIONES E LA LUZ DE LA TEORÍA HISTÓRICO-CULTURAL}

Resumen: Este artículo pretende analizar el desarrollo del lenguaje escrito y el desarrollo intelectual del niño en edad escolar, haciendo hincapié en las etapas de la prehistoria de la escritura descritas por Luria (2006). El estudio tiene carácter bibliográfico y a la luz de los fundamentos de la teoría histórico-cultural, busca destacar que, en el ámbito escolar, la labor del profesor se presenta como un diferencial para el desarrollo del lenguaje escrito en el niño, de forma intencionada y objetiva, teniendo en cuenta el camino ya recorrido por éste. Como resultado, se observa que cuando la actividad es acorde con el nivel de desarrollo del niño, promoverá un nivel más alto, lo que proporcionará la posibilidad de apropiarse de conocimientos más complejos. En otras palabras, el aprendizaje promueve el desarrollo psíquico del niño y éste, a su vez, permite nuevos aprendizajes.

Palabra llave: Lenguaje escrito. Etapas de la pre-escrita. Desarrollo intelectual del niño. 


\section{Introdução}

Considerando que os desvios no processo de desenvolvimento da escrita são comuns e se estendem para além dos anos iniciais, observa-se que a alfabetização da criança se configura como um dos principais desafios da educação. Entendemos a qualidade e a complexidade requeridas nesse período, que se move em direção aos saberes do professor alfabetizador e suas relações com a educação escolar. Nessa direção, com o objetivo de analisar o desenvolvimento da escrita e o desenvolvimento intelectual da criança em idade escolar, tomamos parte da pesquisa de Mestrado em Ensino, em que a apropriação da linguagem escrita se apresenta como um divisor de águas no processo de desenvolvimento cultural e psíquico da criança.

Quando analisamos o processo de alfabetização em idade escolar, nos deparamos com a seguinte indagação: Como se dá o desenvolvimento da linguagem escrita na criança? Para responder a esta questão nos apoiamos em estudos dos autores da teoria históricocultural, como Vigotski (1995, 2000, 2005, 2006), Luria (2006a, 2006b), enfatizando o desenvolvimento da linguagem escrita e sua intelectualização por meio da sistematização das atividades escolares.

No primeiro momento, abordamos o processo de desenvolvimento da linguagem da criança, com destaque para a linguagem escrita e as funções psíquicas superiores. Ao analisar o processo de apropriação da escrita, considera-se importante compreender que a criança tem contato com esse sistema muito antes de entrar na escola. Dessa forma, no segundo momento, voltamos a atenção para a escrita desenvolvida pela criança, antes dela adentrar o contexto escolar, descrevendo os estágios que Luria (2006b) denominou de pré-escrita.

Se considerarmos que a apropriação da linguagem escrita irá interferir no processo de desenvolvimento intelectual da criança e que, antes de ter contato com as atividades de alfabetização, a criança passa por um processo de pré-escrita, faz-se necessário destacar, no terceiro momento, a importância do trabalho do professor e do ensino escolar neste processo. 


\section{Desenvolvimento da linguagem escrita na criança}

Até o desenvolvimento das pesquisas de Vigotski, no início do século XX, na União Soviética, a prática do ensino da escrita ocupava um lugar mínimo, se levarmos em consideração a sua importância para o desenvolvimento cultural da criança. O ensino da escrita, conforme destaca Vygotski (1995), se restringia ao traçado das letras e formação de palavras, assim não se ensinava a linguagem escrita e sua função, mas sim a ortografia e caligrafia, fato esse que se perpetua até os dias atuais.

A linguagem escrita era considerada pela psicologia, como um hábito motor complexo, pois estava relacionado ao desenvolvimento das habilidades motoras das mãos. Esse posicionamento não aprofundava os estudos da linguagem escrita como um sistema, cujo domínio promove mudanças em todo desenvolvimento psíquico da criança. Em contrapartida, Smirnov et al. (1969) aponta que a aquisição da linguagem escrita apresenta grande importância para o desenvolvimento da criança em idade escolar, pois irá ampliar suas possibilidades de se apropriar de novos conhecimentos.

Ao analisar o psiquismo da criança em processo de alfabetização, Vygotski (1995) defende que o domínio da linguagem escrita é um divisor de águas no desenvolvimento intelectual da criança em período escolar. Além disso, o autor destaca que o contato com a linguagem escrita promove considerável desenvolvimento das funções psíquicas superiores, no entanto, a criança começa a desenvolver sua escrita muito antes de entrar na escola.

Na perspectiva da teoria histórico-cultural, as funções psíquicas superiores são estruturas que se desenvolvem no processo cultural, como a memória mediada, a atenção voluntária, pensamento, linguagem, imaginação, percepção, entre outras. Essas funções são desenvolvidas por meio das relações do indivíduo com o mundo exterior e não de forma natural. Por conseguinte, o desenvolvimento da linguagem oral, se apresenta como pressuposto para a compreensão do desenvolvimento da escrita na criança.

Sokolov (1969) destaca que a linguagem permite que nos dirijamos a outras pessoas exercendo influências sobre ela. O autor aponta que toda comunicação exercerá alguma influência sobre o outro. Dito isso, remetemo-nos às atividades escolares, que estão diretamente ligadas à linguagem, a signos e significados, à linguagem interior do 
sujeito e à exterior. Assim, a organização dessas atividades deve levar em consideração as diferentes formas de linguagem e de representação do pensamento.

É importante destacar que antes de entrar em contato com as atividades escolares de alfabetização, a criança já possui contato com a linguagem escrita. Assim, é possível observar nos experimentos de Luria (2006b), que quando a criança entra na escola, já passou por estágios de desenvolvimento da escrita, como explica o autor:

O momento em que uma criança começa a escrever seus primeiros exercícios escolares em seu caderno não é, na realidade, o primeiro estágio de desenvolvimento da escrita. As origens deste processo remontam a muito antes, ainda na pré-história do desenvolvimento das formas superiores do comportamento infantil; podemos até mesmo dizer que quando uma criança entra na escola, ela já adquiriu um patrimônio de habilidades e destrezas que a habilitará a aprender a escrever em um tempo relativamente curto (LURIA, 2006b, p. 143).

A partir dessa proposição, também para Smirnov et al. (1969) a criança, ao entrar na escola, já desenvolveu as leis objetivas do idioma, como instrumento para comunicação oral, no entanto, nesse momento o estudo da língua materna passa a ser apresentado à criança de maneira organizada. Vale lembrar que à educação escolar cabe o papel de organizar as atividades escolares, de maneira que essa propicie a apropriação dos conhecimentos que a criança ainda não tem domínio, como a linguagem escrita.

Em suas pesquisas Vygotski (1995) assevera que a apropriação da linguagem escrita é considerada como a primeira fase do desenvolvimento cultural da criança, relacionada à aprendizagem de um sistema de meios de representação organizados no processo de desenvolvimento cultural humano. Contudo, para que esse processo seja incorporado pela criança, ou seja, para que a linguagem oral se converta em linguagem escrita, é necessário um complexo processo de desenvolvimento que se inicia antes da escolarização e se efetiva por meio do trabalho sistematizado do professor.

Diante da constatação da importância da linguagem escrita para o desenvolvimento psíquico da criança, surge-nos o seguinte questionamento sobre esse processo: o que significa dominar ou desenvolver a linguagem escrita? Vygotski (1995) respondeu esse questionamento quando afirmou que o mesmo consiste na criança 
dominar o sistema simbólico, isto é, utilizar letras e sinais gráficos para expressar-se. Além disso, o autor ainda destacou que a linguagem escrita está relacionada a um sistema de signos que estão diretamente ligados a sons, à linguagem oral, que por sua vez são representações de objetos e relações reais. Ademais, o autor afirma que durante esse processo são observadas diversas transformações de avanços e retrocessos, ou seja, o caminho percorrido pela criança no desenvolvimento da linguagem escrita não é linear, além de avanços e novas formas de escrita, apresentam-se também processos regressivos. Destarte, na medida em que a criança desenvolve uma nova técnica ${ }^{3}$ de escrita, todo o processo sofre um retrocesso, pois ela volta a utilizar técnicas anteriores que já dominava, visto que no início se sente insegura para utilizar a nova técnica.

Luria (2006a) enriquece a resposta ao nosso questionamento quando descreve o que é a escrita:

Escrever é uma das funções culturais típicas do comportamento humano. Em primeiro lugar, pressupõe o uso funcional de certos objetos e expedientes com signos e símbolos. Em vez de armazenar diretamente alguma ideia em sua memória, uma pessoa escreve-a, registra-a fazendo uma marca que, quando observada, trará de volta a mente a ideia registrada (LURIA, 2006a, p. 99).

Apesar de seu contato com os signos da linguagem escrita se iniciar desde muito cedo, a habilidade de utilizá-lo se desenvolve um pouco tarde na criança. De acordo com Luria (2006a), na idade pré-escolar podemos observar que esta habilidade se apresenta ainda fora do alcance da criança. Para ilustrar suas considerações, o autor exemplifica que durante uma brincadeira podemos solicitar a uma criança de três a quatro anos que anote algo que precisa se recordar no decorrer da brincadeira, observa-se em alguns casos que a criança não compreende a ideia de utilizar algum objeto ou marca como instrumentos para recordar algo. Assim, ao ditar a uma criança duas ou três palavras ou sentenças, solicitando que as escreva ou desenhe para se lembrar posteriormente, provavelmente ela fará rabiscos sem nenhuma conexão com o que the foi ditado, de maneira que seu registro não servirá como recurso de auxílio para a memória, assim como seus registros não irão contribuir para que se lembre depois.

\footnotetext{
${ }^{3}$ O termo técnica se apoia em Luria (2006b) quando explica que são exercícios escolares de aprendizagem da escrita inicial.
} 
Nesse âmbito, considerando a importância do contato que a criança tem com a escrita antes de entrar na escola, nos propomos a discorrer sobre os estágios da préescrita que ela percorre antes de se apropriar do sistema simbólico.

\section{Estágios da história da pré-escrita percorridos pela criança}

É preciso, em primeiro lugar, lembrar que as pesquisas sobre a história da préescrita, desenvolvida por Vigotski e Luria, teve início no momento em que a União Soviética passava por grandes transformações sociais. De acordo com Francioli (2013), nesse período, $73 \%$ da população era analfabeta. Foi nesse contexto que Luria desenvolveu sua pesquisa sobre a escrita da criança.

$\mathrm{Na}$ proposição da teoria histórico-cultural, Luria (2006b) identificou diversos estágios percorridos pela criança no percurso de apropriação da linguagem escrita até chegar ao estágio da escrita convencional. Somente após ter passado por todos os estágios de desenvolvimento da linguagem escrita, a criança atinge o nível do homem "civilizado", como afirma o autor.

Os estudos de Luria (2006b) demonstraram que os estágios da pré-escrita têm três aspectos que são: o instrumental, o cultural e o histórico. E, a melhor maneira de estudar essa pré-história, as várias tendências e fatores envolvidos consiste em descrever os estágios, que podem ser observados quando uma criança desenvolve sua habilidade para escrever e os fatores que a habilitam a passar de um estágio para outro superior.

Quais seriam esses estágios que antecedem o processo de alfabetização da criança? Luria (2006b) denomina esses estágios da seguinte forma:

a) estágio dos rabiscos ou fase dos atos imitativos, primitivos, pré-culturais e préinstrumentais - isto significa que neste estágio a criança tenta imitar a escrita dos adultos. Nesse estágio a criança não sabe o que está escrevendo, a relação dela com os rabiscos é puramente externa, intuitiva e não serve para lembrar-se mais tarde da sentença.

b) estágio da escrita não diferenciada - a criança utiliza os rabiscos não para ler, mas para lembrar-se do que the foi dito. A relação da criança com os rabiscos é puramente externa, não tem significado para ela. É por isso que o ato de escrever pode ser dissociado de forma tão completa da sentença escrita. 
c) estágio da escrita diferenciada - Neste estágio, a criança substitui a escrita não diferenciada pela escrita diferenciada. Para observar este estágio, é preciso introduzir dois fatores que levam a criança da fase não diferenciada para a atividade gráfica diferenciada: números e formas. A criança usa desenhos para se lembrar do que escreveu, cada criança desenvolve uma forma de se recordar da sentença ditada.

d) estágio da escrita por imagens (pictográfica) - Durante o estágio da escrita diferenciada, o uso de fatores como quantidades e formas distintas é que permitem que a criança avance para pictografia. $\mathrm{O}$ uso dos desenhos passa a ser uma forma de recordar e, pela primeira vez, o desenho começa a convergir para uma atividade intelectual complexa. O estágio pictográfico apresenta-se desenvolvido principalmente em crianças de cinco e seis anos, representando a experiência que a criança tem com os desenhos infantis. A princípio pode representar brincadeiras e depois se torna um meio de registro.

e) 10 estágio do desenvolvimento da escrita simbólica: neste estágio a relação da criança com a escrita é puramente externa. A criança ainda não aprendeu a função da escrita, mas pode usar letras do alfabeto. Nessa fase a criança usa os códigos linguísticos de maneira externa, não entende os mecanismos do uso dos signos na escrita. Neste estágio a criança pode registrar letras que conhece, sem se lembrar do que foi ditado.

Luria (2006b, p. 180-181) declara:

[...] que a pré-história da escrita infantil descreve um caminho de gradual diferenciação dos símbolos usados. No começo, a criança relaciona-se com coisas escritas sem compreender o significado da escrita; no primeiro estágio, escrever não é um meio de registrar algum conteúdo especifico, mas um processo autocontido, que envolve a imitação de uma atividade do adulto, mas que não possui, em si mesmo, significado funcional. Esta fase é caracterizada por rabiscos não diferenciados; a criança registra qualquer ideia com exatamente os mesmos rabiscos. Mais tarde - e vimos como isso de desenvolve - começa a diferenciação: símbolo adquire um significado funcional e começa graficamente a refletir o conteúdo que a criança deve anotar.

Essa forma de representar a pré-história da escrita expressa que uma compreensão dos mecanismos ocorre muito depois do domínio exterior da escrita e que, nos primeiros estágios de aquisição, esse domínio pela criança é puramente externo. Ela 
compreende que pode usar signos para escrever qualquer coisa, mas não entende ainda como fazê-lo.

De acordo com Luria (2006b), o estudo histórico do desenvolvimento da escrita na criança, levando em consideração seu desenvolvimento cultural, antes dela entrar na escola, permite-nos a compreensão da gênese do processo de desenvolvimento da linguagem escrita. Assim, o autor salienta que quando a criança entra na escola, ela já adquiriu habilidades para se desenvolver em um tempo consideravelmente curto, se olharmos o tempo que ela demorou para se constituir na história do desenvolvimento cultural humano, ou seja, ao entrar na escola já aprendeu uma série de técnicas da escrita e teve contatos com diversos signos que facilitaram sua aprendizagem.

Nessa perspectiva, Luria (2006b) ao discorrer sobre o processo de desenvolvimento da escrita na criança, pontua que essa função se desenvolve por meio da mediação, ou seja, está relacionada a situações que são apresentadas à criança. Neste sentido, ele destaca que para a criança conseguir registrar algo, faz-se necessário duas condições favoráveis a isso: em primeiro lugar, o objeto de registro precisa representar interesse à criança ou que tenha uma função ligada ao interesse da criança. Em segundo lugar, a criança precisa ter atingido um nível de desenvolvimento, ao qual ela seja capaz de dominar seu comportamento e utilizar os instrumentos que lhe são apresentados.

É preciso esclarecer que, em um certo momento do desenvolvimento, o indivíduo começa a utilizar técnicas que auxiliam a organização das funções psíquicas. Neste sentido, as operações matemáticas e a escrita se apresentam como técnica de auxílio para as funções psíquicas superiores, como podemos observar nas considerações de Luria (2006b, p. 146):

\begin{abstract}
A escrita é uma dessas técnicas auxiliares usadas para fins psicológicos; a escrita constitui o uso funcional de linhas, pontos e outros signos para recordar e transmitir ideias e conceitos. Exemplos de escritas floreadas, enfeitadas, pictográficas mostram quão variados podem ser os itens arrolados como auxílios para retenção e transmissão das ideias, conceitos e relações.
\end{abstract}

Pelo fato das funções psíquicas superiores se desenvolverem desde a mais tenra idade, a escrita passa a ser utilizada como função de auxílio psicológico em um momento um pouco tarde do desenvolvimento da criança, considerando que ela compreende a 
função da escrita após ser inserida no processo de alfabetização, que acontece no primeiro ano do ensino fundamental. Nesse período, a criança precisa ter 6 anos de idade ou próximo a completá-lo.

Ao apresentar os experimentos realizados por Luria ${ }^{4}$, Vygotski (1995) destaca que a criança de três ou quatro anos de idade, ainda não compreende a escrita como um meio para recordar-se de algo. $\mathrm{O}$ ato de escrever, ou rabiscar, nesta fase do desenvolvimento da escrita é puramente imitativo, assim, a criança muda sua forma de registrar quando observa como um colega de mais idade faz o registro do que lhe foi solicitado. No entanto, o simples fato de mudar sua forma de registro, não significa que a criança compreendeu a função da escrita, "a escrita da criança não desempenha ainda uma função mnemônica" (LURIA, 2006b, p. 155), ou seja, não pode ser utilizada como recurso auxiliar da memória.

Os resultados apresentados por Luria (2006b) demonstram que o processo de desenvolvimento da escrita da criança percorre um longo caminho, desde a escrita de rabiscos não diferenciados, a substituição por imagens e posteriormente a utilização de signos. Esse caminho, além de representar o desenvolvimento da escrita, também mostra sua história durante o desenvolvimento cultural humano, ou seja, o caminho percorrido pela criança no processo da construção da escrita é semelhante ao percorrido pela humanidade, porém, em tempo mais curto.

É notado durante os experimentos de Luria (2006b), que quando a criança observa que não pode marcar todas as palavras da mesma maneira, modifica seus rabiscos tentando representar de maneira diferente as palavras solicitadas. $\mathrm{O}$ autor anuncia um grande avanço quando a criança sofre uma transição em sua forma de registro, passando de simples rabiscos a registros pictográficos. Para Luria (2006b) a escrita por imagens apresenta-se como um momento avançado do desenvolvimento da criança e em geral acontece quando esta já está na pré-escola.

A escrita pictográfica está baseada nos desenhos infantis, neste caso, explica Luria (2006b), o desenho se apresenta como um meio, desempenhando uma função voltada a uma situação. É preciso ter claro que o desenho espontâneo apresenta características diferentes da escrita pictográfica, pois não possui função mnemônica, ou seja, não está voltada à recordação de algo.

\footnotetext{
4 Os experimentos encontram-se demonstrados no texto "O desenvolvimento da escrita na criança." (LURIA, 2006b, p. 143-190).
} 
Ao abordar a escrita pictográfica, Vygotski (1995, p. 192) analisa que ela ocorre por volta dos cinco anos de idade, destacando que "o desenho infantil é uma etapa prévia a linguagem escrita". O desenho infantil é uma representação gráfica de algo e está diretamente ligado à memória da criança, pois ao representar algo por meio de desenho, a criança está buscando características já memorizadas por ela. Da mesma maneira que a linguagem escrita, o desenho não se desenvolve de maneira puramente mecânica, mas sim é resultado de seu desenvolvimento cultural, ou seja, é uma representação de signos já incorporados pela criança.

Além do desenho, Vygotski (1995) acentua que os jogos infantis também se apresentam como fator importante no desenvolvimento da linguagem escrita, no sentido de que, durante os jogos, a criança está em constante contato com os significados dos objetos e, por vezes, muda-os durante o jogo. O autor explica que os jogos simbólicos podem ser compreendidos como um sistema de linguagem muito complexo, contribuindo com o desenvolvimento dos signos e significados. Em um jogo simbólico, um objeto pode assumir um significado totalmente oposto ao que representa, como é o caso de uma vassoura que pode virar um cavalo, ou uma garrafa pet que pode virar um carrinho.

Neste sentido, o desenvolvimento da linguagem e dos significados das palavras seguem o mesmo caminho dos jogos simbólicos, ou seja, um objeto é representado pela criança por meio de rabiscos, depois de desenhos e com o desenvolvimento da escrita ela passa a utilizar a palavra para representar esse objeto. Como nos jogos, um objeto pode ser representado por outro, os desenhos podem representar simbolicamente um objeto, também as palavras são representações simbólicas de objetos.

De acordo com Luria (2006b), quando a criança entra na escola, não se apropria de imediato dos códigos linguísticos e começa a escrever. Assim, desde o momento "em que uma criança começa, pela primeira vez, aprender a escrever até a hora em que finalmente domina essa habilidade há um longo período [...]." (LURIA, 2006b, p. 180). Isso representa que quando a criança tem contato com a escrita, por meio das atividades organizadas pelo professor, ela se encontra no limite entre as formas primitivas de escrita e a nova forma cultural. Neste momento, a criança ainda não domina as técnicas de escrita alfabética e não superou a primitiva, ou seja, a partir do trabalho de alfabetização, a criança começa a aprender a ler e reconhecer algumas letras, no entanto, nesta fase inicial, 
a criança apenas pode utilizar os signos (letras), mas não domina ainda as técnicas de escrita.

Nas palavras do autor:

Ela compreende que pode usar signos para escrever qualquer coisa, mas não entende ainda como fazê-lo. Torna-se assim inteiramente confiante em sua escrita, mas ainda é capaz de usá-la. Acreditando integralmente nesta nova técnica, no primeiro estágio do desenvolvimento da escrita simbólica, a criança começa com uma fase de escrita não diferenciada pela qual já passara muito antes. (LURIA, 2006b, p 181).

Observa-se assim, que a criança neste estágio de desenvolvimento da escrita, ainda não compreendeu sua função e utiliza uma letra repetidamente para representar sentenças diferentes. Esta fase será superada com o surgimento de uma nova fase no desenvolvimento da escrita.

Os experimentos aplicados por Luria, destaca Vygotski (1995), permitiram compreender o caminho percorrido pelo desenvolvimento da escrita na criança, desde os rabiscos primitivos até a utilização dos signos linguísticos. Quando se fala em utilização dos signos, não estamos nos referindo a saber traçar as letras, pois Vigotski deixa claro que a criança que sabe traçar as letras, mas não compreende o mecanismo da escrita, está apenas reproduzindo movimentos. A criança começa a compreender os mecanismos da escrita, quando compreende que o desenho, assim como as letras não representam apenas coisas, mas que podem também representar a fala.

Foi essa descoberta que levou a humanidade ao genial método da escrita por letras e palavras, e essa mesma descoberta leva a criança a escrever as letras. Do ponto de vista psicológico este fato equivale a passar do desenho de objetos ao das palavras. É difícil determinar como ocorre tal transição uma vez que as investigações não chegaram ainda a resultados determinados e os métodos de ensino da escrita comumente aceitos não permitem observar esta transição (VIGOTSKI, 1995, p. 197, tradução nossa).

A partir deste apontamento, o autor declara que os conhecimentos psicológicos consideravam exageradas as conclusões dos experimentos realizados por seu grupo, no 
que se refere ao jogo, desenho e escrita. As pesquisas vigotskianas demonstraram que estas etapas se apresentam como diferentes momentos do processo de desenvolvimento da linguagem escrita, apesar dos saltos e rupturas serem grandes de um momento a outro. Para Vigotski (1995, p. 197, tradução nossa) se trata "de uma linha única na história da escrita que leva as formas superiores da linguagem escrita". Essa forma superior se dá quando a criança compreende a relação entre a escrita e a fala, ou seja, compreende que por meio da escrita pode-se representar a fala.

O desenvolvimento da linguagem escrita na criança, desde as primeiras atividades está diretamente relacionada ao desenvolvimento das funções psíquicas superiores. Smirnov et al. (1969) exemplifica este processo ao afirmar que a aprendizagem da leitura desenvolverá a atenção visual e auditiva, onde a criança precisará distinguir os sons e as letras. Para responder as questões levantadas pelo professor, a criança precisará da atenção e da percepção. Observa-se ainda novas exigências ao uso da memória, pois a criança precisará fixar e recordar novos conceitos.

Vygotski (1995) enfatiza que a verdadeira linguagem escrita se desenvolve passando do registro de objetos ao registro de palavras. O ensino escolar não só é responsável pela organização e desenvolvimento da escrita da criança, como também é responsável pelo seu aperfeiçoamento. Assim, considerando que a linguagem escrita é processo que se efetiva no contexto escolar, buscaremos discorrer sobre o trabalho do professor no desenvolvimento da criança.

\section{O trabalho do professor e o desenvolvimento psíquico da criança em processo de alfabetização}

Nos estudos sobre o desenvolvimento da linguagem escrita na criança, foi destacado que este processo se inicia antes do seu ensino sistematizado, no entanto, um bom ensino possibilita que a criança se aproprie dos signos linguísticos, de maneira que seja capaz de utilizá-los em diversos contextos.

Observamos em Martins (2015); Vygotski (1995); Luria (1979); Facci (2004) que o desenvolvimento da criança está diretamente ligado à sua interação com outros sujeitos já desenvolvidos. Isso demonstra que é por meio da apropriação do conhecimento 
desenvolvido pelas gerações anteriores que o sujeito irá desenvolver-se, tanto no ambiente familiar quanto no ambiente escolar.

A educação escolar se apresenta como responsável pela mediação entre o aluno e o conhecimento historicamente produzido, sendo a linguagem escrita um complexo sistema de signos e significados constituídos pela humanidade. Essa apropriação dos conhecimentos, por meio do trabalho sistematizado, irá impulsionar o desenvolvimento intelectual da criança. Neste sentido, Eidt (2009) acrescenta que o desenvolvimento psíquico da criança não se dá de maneira biológica ou natural, mas é resultado do trabalho realizado pelo professor na mediação entre sujeito e o conhecimento elaborado.

Martins (2015) destaca que o processo de internalização do conhecimento, que irá promover o desenvolvimento psíquico do sujeito e de suas especificidades humanas, ocorre por meio da relação de outros sujeitos em processos educativos. Por processo educativo é preciso compreender não apenas o que acontece dentro do âmbito escolar, mas a apropriação dos conteúdos escolares em todas suas dimensões. No entanto, não podemos descartar os conhecimentos espontâneos desenvolvidos pela criança em seu meio social, visto que para Vigotski (2000), tanto os conhecimentos espontâneos, quanto os científicos, são importantes para o desenvolvimento do indivíduo.

Por conhecimentos científicos apropriados em processo de alfabetização, compreendemos como as normas cultas da linguagem escrita, enquanto os conhecimentos espontâneos estão relacionados às tentativas de escrita que a criança faz ao imitar um adulto ou criança alfabetizada. Como observamos anteriormente, a criança antes mesmo de ter contato com a escola, já apresenta um desenvolvimento da escrita, mesmo não sistematizada. Para Luria (2006a), a pré-escrita da criança, permite que ela se aproprie da escrita formal em um tempo consideravelmente curto.

Tanto no desenvolvimento dos conceitos espontâneos quanto nos científicos, um dos fatores determinantes do processo é a mediação entendida como processo cultural que estabelece uma ligação entre instrumentos e signos, fatores responsáveis pelo desenvolvimento humano, ou seja, "ocorre o amadurecimento das funções psicológicas superiores da criança com o auxílio e a participação do adulto" (VIGOTSKI, 2000, p. 244). O autor ainda destaca que o diferencial do processo educativo é o fato de que o conhecimento é transmitido ao aluno de maneira sistematizada. 
Esse entendimento pressupõe que a aprendizagem que ocorre na idade escolar se apresenta como momento decisivo para o processo de desenvolvimento psíquico da criança, mediante a assimilação dos conteúdos científicos. Nesse aspecto, Duarte (2008) enfatiza que a incorporação dos conhecimentos científicos se dá por meio da educação escolar, na superação dos conhecimentos cotidianos ao qual a criança tem contato em seu meio social. A introdução dos instrumentos e signos no processo de alfabetização, permitirá que a criança supere as formas primitivas de escrita e se aproprie da escrita simbólica.

Facci (2004) e Duarte (2008) defendem que para Vigotski o ensino dos conhecimentos científicos promoverá o desenvolvimento dos conceitos na criança por meio de um procedimento metodológico analítico que envolva as operações mentais de abstração e generalização. Observa-se no desenvolvimento dos conceitos o processo dialético, onde com base nos conceitos espontâneos já formados na criança, se formam os conceitos científicos e estes por sua vez permitem a assimilação de novos conceitos. Nessa direção Friedrich (2012) destaca que os conceitos científicos são generalizações de segunda ordem, pois sempre estão apoiados em conceitos já internalizados pela criança.

Nessa perspectiva, compreende-se que a educação escolar nunca parte do zero, porque a criança já possui uma trajetória de desenvolvimento pré-escolar, entretanto, o ensino não pode limitar-se ao que a criança já sabe, mas conduzi-la a se apropriar de um novo tipo de conhecimento.

Referindo-se certamente à educação escolar, Saviani (2005) diz que o clássico na educação é a transmissão do saber sistematizado, o conhecimento científico, que para Vigotski (2005) promove o desenvolvimento intelectual da criança. Quando abordamos a questão da apropriação do conhecimento científico, este não acontece de maneira não intencional, mas faz parte de um processo organizado e sistematizado, direcionado por alguém que já se apropriou destes conhecimentos, no caso do ensino escolar, o professor. Nesse sentido, Kostiuk (2005) aponta que o ensino não deve limitar-se à transmissão do conhecimento, mas sim deve estar voltado ao desenvolvimento do pensamento do aluno e, para isso, se faz necessário que o professor organize seu trabalho de maneira que conduza ao desenvolvimento mental do mesmo.

Para esclarecer essa dinâmica, Facci (2004) assinala que o professor, durante o processo de ensino e aprendizagem, assume um papel fundamental na transmissão do 
conhecimento, conduzindo o aluno à solução dos problemas escolares, de maneira que este consiga utilizar os conhecimentos práticos e relacioná-los com os conhecimentos teóricos. O professor assume um importante papel para a psicologia histórico-cultural e para a pedagogia histórico-crítica, pois, por meio dos conhecimentos, os alunos desenvolverão os conceitos científicos e as funções psíquicas superiores. Um dos exemplos destacado por Vigotski (2005) refere-se à linguagem escrita, ou seja, quando a criança se apropria desse código linguístico, será possível observar um considerável desenvolvimento psíquico e um alto grau de abstração.

\section{Conclusão}

A apropriação da linguagem escrita, por longo período, foi considerada um ato mecânico, porém os autores da teoria histórico-cultural demonstraram que esse processo além de não ser um ato mecânico, pois implica uma apropriação complexa, também promove o desenvolvimento das funções psíquicas da criança, sendo assim a primeira fase de apropriação cultural.

No processo de apropriação da linguagem escrita e desenvolvimento intelectual da criança, a organização das atividades escolares se destaca como elemento fundamental, visto que essas estão repletas de linguagens, signos e significados. É justamente a sistematização das atividades escolares que diferencia a aprendizagem escolar dos conhecimentos já apropriados pela criança em seu convívio social.

Ao analisar o processo de desenvolvimento da escrita na criança, observamos nos estudos de Luria que, antes mesmo de entrar na escola, a criança já apresenta contato e tentativas de escrita. Assim, para chegar ao nível do processo de alfabetização, ela percorre diferentes estágios até se apropriar da linguagem escrita em um tempo relativamente curto.

Ao entrar em contato com a escrita, por meio das atividades escolares, a criança inicia a transição da escrita primitiva para a escrita cultural. Nos primeiros momentos de desenvolvimento da escrita a criança não compreende sua função, sendo essa uma atividade imitativa. Nessa situação, a memória, surgirá posteriormente, porém em todas 
as etapas do desenvolvimento da escrita haverá relação com o desenvolvimento das funções psíquicas superiores.

Neste longo processo, o desenho destaca-se como recurso importante na representação das ideias. Salienta-se que mesmo no processo sistematizado de apropriação da escrita, o desenho se apresenta como forte aliado no desenvolvimento psíquico da criança, visto que por meio do mesmo é possível explorar os elementos da narrativa.

Se o desenvolvimento intelectual se dá a partir da apropriação dos conhecimentos historicamente produzidos e essa apropriação acontece nas relações com outros indivíduos, a escola se apresenta como espaço destinado a esse fim. Logo, ao ensino escolar fica incumbida a responsabilidade de desenvolvimento e aperfeiçoamento da linguagem escrita, sendo o professor o principal responsável pela organização das atividades que irão propiciar avanços nesse processo.

Assim, ao concluir essas considerações, reafirmamos o papel que cabe ao professor alfabetizador que, ao sistematizar as atividades de maneira objetiva, leva em conta o caminho percorrido pela criança. Nesse aspecto, ao organizar seu trabalho, o professor deverá considerar o nível de desenvolvimento de seus alunos, pois as atividades não poderão estar muito aquém e nem muito além do nível de desenvolvimento da turma. Assim, quando a atividade está de acordo com o nível de desenvolvimento da criança, promoverá nela um nível mais elevado, o que propiciará a esta a possibilidade de se apropriar de conhecimentos mais complexos. Em outras palavras, a aprendizagem promove o desenvolvimento psíquico da criança e este por sua vez possibilita novas aprendizagens.

\section{Referências}

DUARTE, Newton. Sociedade do conhecimento ou sociedade das ilusões? Quatro ensaios críticos-dialéticos em filosofia da educação. Campinas, SP: Autores Associados, 2008.

EIDT, Nadia Maria. A educação escolar e a relação entre o desenvolvimento do pensamento e a apropriação da cultura: a psicologia de A. N. Leontiev como referência nuclear de análise. 2009. 257 f. Tese (Doutorado) - Faculdade de Ciências e Letras de Araraquara, Universidade de São Paulo, Araraquara, 2009. 
FACCI, Marilda Gonçalves Dias. Valorização ou esvaziamento do trabalho do professor? um estudo crítico-comparativo da teoria do professor reflexivo, o construtivismo e da psicologia vigotskiana. Campinas, SP: Autores Associados, 2004.

FRANCIOLI, Fátima Aparecida Souza. Os estágios que constituem a história da pré-escrita: reflexões a partir dos experimentos realizados com crianças não alfabetizadas. Horizontes: revista de educação. Dourados, v. 1, n. 1, p. 73-85, jan./jun. 2013.

FRIEDRICH, Janette. Lev Vigotski: mediação, aprendizagem e desenvolvimento: uma leitura filosófica e epistemológica. Tradução de Anna Rachel Machado e Eliane Lousada. Campinas: Mercado de Letras, 2012.

KOSTIUK, G. S. Alguns aspectos da relação recíproca entre educação e desenvolvimento da personalidade. In: LEONTIEV, Alexis N.; VYGOTSKY, Liev Semionovitch; LURIA, Alexandre Romavich. Psicologia e pedagogia: bases psicológicas da aprendizagem e do desenvolvimento. Tradução de Rubens Eduardo Frias. São Paulo: Centauro, 2005.

LURIA, Alexander Romanovich. Curso de Psicologia Geral: linguagem e pensamento. v. IV. Rio de Janeiro, Civilizações Brasileira, 1979

LURIA, Alexandre Romanovich. A psicologia experimental e o desenvolvimento infantil. In: VIGOTSKII, Liev Semionovitch; LURIA, Alexandre Romavich; LEONTIEV, Alexis N. Linguagem, desenvolvimento e aprendizagem. 10. ed. São Paulo: Ícone, 2006a. p. 85-102.

LURIA, Alexandre Romanovich. O desenvolvimento da escrita na criança. In: VIGOTSKII, Liev Semionovitch; LURIA, Alexandre Romavich; LEONTIEV, Alexis N. Linguagem, desenvolvimento e aprendizagem. São Paulo: Ícone, 2006b. p. 143-189.

MARTINS, Lígia Márcia. O desenvolvimento do psiquismo e a educação escolar: contribuições à luz da psicologia histórico cultural e da pedagogia histórico-crítica. 2. ed. Campinas: Editores Associados, 2015.

SAVIANI, Demerval. Pedagogia histórico-crítica: primeiras aproximações. 9. ed. Campinas, SP: Autores Associados, 2005.

SMIRNOV, Anatoli A. et al. Psicologia. México: Grijalbo, 1969.

SOKOLOV, E. N. La percepción. In: SMIRNOV, Anatoli A. et al. Psicologia. México: Grijalbo, 1969. p. 144-176.

VYGOTSKI, Lev Semenovich. Obras escolhidas. Madri: Visor, 1995. t. 3.

VYGOTSKI, Lev Semenovich. A construção do pensamento e da linguagem. Tradução de Paulo Bezerra. São Paulo: Martins Fontes, 2000.

VYGOTSKI, Lev Semenovich. Aprendizagem e desenvolvimento intelectual na criança. In: LEONTIEV, Alexis N.; VYGOTSKY, Liev Semionovitch; LURIA, Alexandre Romavich. Psicologia e 
pedagogia: bases psicológicas da aprendizagem e do desenvolvimento. São Paulo: Centauro, 2005.

VYGOTSKI, Lev Semenovich. Aprendizagem e desenvolvimento intelectual na idade escolar. In: VIGOTSKII, Liev Semionovitch; LURIA, Alexandre Romavich; LEONTIEV, Alexis N. Linguagem, desenvolvimento e aprendizagem. 10. ed. São Paulo: Ícone, 2006. p. 103-118.

Recebido em: 23 out. 2020

Aceite em: 20 dez. 2020 